\title{
Agôn
}

Revue des arts de la scène

Critiques | Saison 2012-2013

\section{When the mountain changed its clothing, de Heiner Goebbels}

Lorsque les jeunes filles changent d'humeur

\section{Marion Siéfert}

\section{CpenEdition}

\section{Journals}

Édition électronique

URL : http://journals.openedition.org/agon/2321

DOI : 10.4000/agon.2321

ISSN : 1961-8581

Éditeur

Association Agôn

Référence électronique

Marion Siéfert, «When the mountain changed its clothing, de Heiner Goebbels », Agôn [En ligne],

Critiques, mis en ligne le 14 novembre 2012, consulté le 23 septembre 2020. URL : http://

journals.openedition.org/agon/2321; DOI : https://doi.org/10.4000/agon.2321

Ce document a été généré automatiquement le 23 septembre 2020.

Association Agôn et les auteurs des articles 


\section{When the mountain changed its clothing, de Heiner Goebbels}

Lorsque les jeunes filles changent d'humeur

\section{Marion Siéfert}

\section{RÉFÉRENCE}

When the mountain changed its clothing, invité au Festival d'Automne à Paris, du 25 au 27 octobre 2012. Les 10 et 11 mai 2013 au Grand Théâtre du Luxembourg.

1 Trente-neuf jeunes filles slovènes entre dix et vingt ans sont assises sur des chaises au bord de la scène. Elles fixent le public, un sourire mutin sur les lèvres qui se change en quelques minutes en une expression de colère sourde. Elles ont changé d'humeur, toutes ensemble et ce bloc menaçant a quelque chose d'inquiétant. Derrière le passage mystérieux de la puberté, cette mutation physiologique et psychique, se dessine dans When the mountain changed its clothing la question des changements politiques à travers lesquels sont passés les Slovènes. 
When the mountain changed its clothing, de Heiner Goebbels

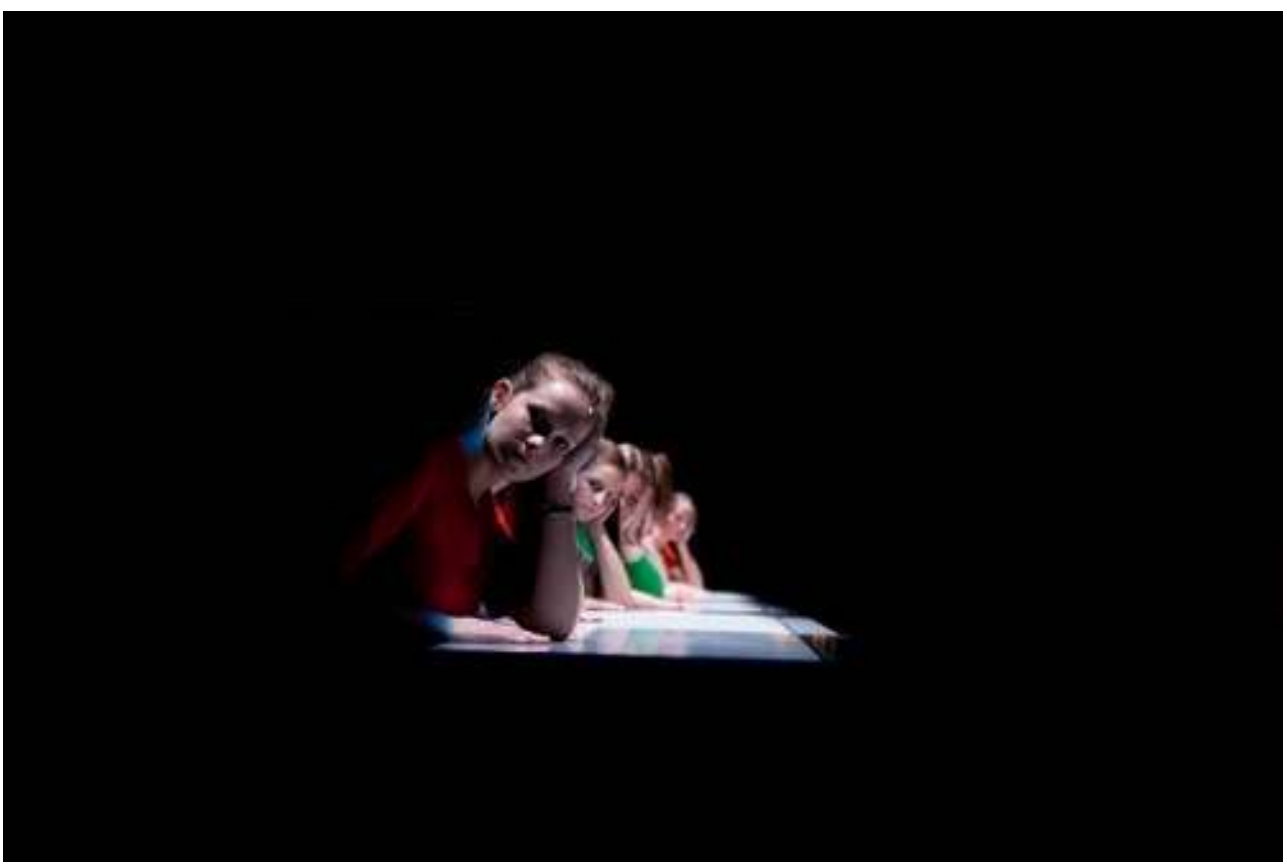

(c) Dorian Šilec Petek

2 Quel est le lien entre cette transformation sociale et politique et cette métamorphose biologique et biographique? Heiner Goebbels, compositeur et metteur en scène, n'apporte pas de réponse, mais propose une forme à cette question dans When the mountain changed its clothing, une collaboration avec les chanteuses du choeur Vocal Theatre Festival Carmina Slovenica que dirige Karmina Šilec. Avec une dextérité vocale et un professionnalisme impressionnant, elles chantent des mélodies du folklore slovène, des compositions de Heiner Goebbels, des chants patriotes de l'époque de Tito, mais aussi Brahms, Schoenberg et Sarah Hopkins; elles parlent en anglais et occupent le plateau durant une heure et demie de beauté et de surprise. Le microcosme personnel de ces jeunes filles est mis en scène par différentes scénettes ciselées sur une petite scène dressée au centre du plateau, dont la simplicité et la fragilité rappellent ces spectacles de fin d'année présentés dans une cour d'école. Éclairées par une lumière de conte de fées, elles ont la forme de miniatures, rythmées par le passage des saisons, abandonnées aux regards du collectif-choeur et des spectateurs. Oscillant entre légèreté enfantine et violence contenue, elles laissent résonner des harmonies politiques et poétiques pour faire jaillir une réflexion sur la société et la condition humaine. La puberté est une période d'intransigeance et de révolte. Il y a peu d'innocence dans When the mountain changed its clothing: on n'y trouve qu'une implacable lucidité.

3 Comment avancer lorsqu'aucune vision de l'avenir n'existe et que le chaos de la situation présente empêche de poser des fondations sereines? Au début du spectacle, le plateau est jonché de chaises renversées, éclairé par une lumière crue et sans concessions. Les yeux fermés, avançant à tâtons, le groupe de jeunes filles traverse la scène, avec pour seul guide une phrase qui les rassure et qu'elles reprennent en chœur, comme un chant que l'on entonnerait dans la nuit pour se donner du courage : «Come. Listen to me. Everything gonna be alright ». Que tout ira bien, on n'en croit pas un mot, mais la force d'entraînement du collectif fascine. Ensemble, ces adolescentes chantent, 
jouent, se débrouillent, changent de direction, alors que toute figure parentale et adulte semble avoir disparu. Seules, elles engagent un rituel qui les fait sortir de l'enfance : qu'elles ouvrent des peluches et fabriquent des nuages avec leur garnissage ouaté, qu'elles changent de vêtements, jouent avec un ballon orange qui se met à flotter comme par magie ou dressent une petite scène sur laquelle elles organisent le passage des saisons, toujours le mystère du féminin côtoie l'apologue et la parabole. Ainsi, les textes de Jean-Jacques Rousseau, Joseph Eichendorff, Adalbert Stifter, Gertrude Stein, Alain Robbe-Grillet, Marlen Haushofer, Marina Abramović et Ian McEwan, convoqués par Heiner Goebbels et dits sur cette petite scène, laissent sourdre une violence latente, renforcée par la force de ce chœur mouvant, avec lequel dialoguent parfois une ou deux adolescentes. Lorsqu'une fillette demande à quoi rêvent les jeunes filles, c'est une voix collective qui lui répond à l'unisson : « au couteau et au sang ».

4 Si les jeunes filles ont changé d'humeur, ce n'est pas seulement parce que l'on a changé de saison, mais parce qu'il est dur de vivre dans une société où l'on ne peut plus régler le problème de la pauvreté. Et comme l'écrit Gertrude Stein de façon si lucide : «il est plus facile de se débarrasser des riches que de se débarrasser des pauvres ». Avec ce théâtre musical, Heiner Goebbels et le Vocal Theatre Festival Carmina Slovenica proposent une forme à la collectivité, une façon d'exister ensemble, par le chant. 